\title{
The effects of 10 -week different exercise interventions on Framingham risk score and metabolic syndrome severity scores in overweight women with type 2 diabetes
}

\author{
Ebrahim Banitalebi ${ }^{*}$, Majid Mardaniyan Ghahfarrokhi ${ }^{2}$, Mohammad Faramarzi $^{3}$, Samira Nasiri ${ }^{4}$ \\ ${ }^{1}$ Associate Professor in Exercise Physiology, Department of Sports Sciences, Shahrekord University, Shahrekord, Iran \\ ${ }^{2} \mathrm{PhD}$ student in exercise Physiology, Department of Sports Sciences, Shahrekord University, Shahrekord, Iran \\ ${ }^{3}$ Associate Professor in Exercise Physiology, Department of Sports Sciences, Shahrekord University, Shahrekord, Iran \\ ${ }^{4} \mathrm{MSc}$ in Exercise Physiology, Department of Sports Sciences, Shahrekord University, Shahrekord, Iran
}

*Corresponding Author: Ebrahim Banitalebi, Tel: +9132818216, Email: banitalebi.e@gmail.com

\begin{abstract}
Background and aims: Type 2 diabetes (T2D) is a strong independent risk factor for cardiovascular disease (CVD). The purpose of this study was to examine the effects of short sprint interval training (SIT) and combined aerobic + resistance training (A+R) on Framingham risk score (FRS) and metabolic syndrome severity scores (MetS score) in overweight women with T2D.

Methods: In this single-blind randomized clinical trial,52 overweight females afflicted with T2D (aged 45-60 years, BMl >30 kg/m2, HbA1C $\geq 6.5 \%)$ were randomly assigned to either SIT $(n=17)$, combined training $(n=17)$, and control groups $(n=18)$. Interventions consisted of SIT or combined aerobic-strength training for 10 weeks. Data were analyzed using a paired t test to compare pretest and posttest results in each group. A one-way ANOVA was employed to compare the number of changes in the experimental and control training groups after 10 weeks.

Results: The results indicated that there were significant differences between the groups in FRS $(P=0.001)$. However, no difference was found in Mets score $(P=0.160)$. In addition, significant differences were observed in FRS between SIT and combined training groups $(P=$ $0.018)$ and also SIT and control groups $(P=0.001)$.

Conclusion: The results highlighted that SIT as compared to the combined training could be an effective strategy to improve FRS and Mets score in women with T2D.

Keywords: Exercise; Framingham Risk Score; Mets scores; T2D
\end{abstract}

Received: 18 February 2018, Accepted: 20 June 2018, ePublished: 10 July 2018

\section{Introduction}

Type 2 diabetes (T2D) is considered as a strong independent risk factor for cardiovascular disease (CVD). Adults with diabetes have 2-4 times more increased risk of developing CVD and stroke (1). Diabetes-related cardiovascular complications are also a major cause of morbidity and mortality in comparison to metabolic dysregulation (2). In addition, the prevalence of obesity increases in the middle of life and decreases upon aging. Besides, women are more likely to be overweight than men (3). Moreover, there is strong evidence indicating that $\mathrm{T} 2 \mathrm{D}$ confers a stronger excess CVD risk in women than men. There are sex-specific pathophysiological differences in metabolic syndrome that could be potentially due to their adverse risk-factor profile (4).

Many researchers have focused on identifying and introducing a large number of combined biomarkers to predict the risk scores of CVD, aiming at evaluating and monitoring responses to therapeutic strategies. Several useful risk prediction equations have been developed in recent years regarding the primary prevention methods of CVD at the individual and clinical levels. It has been shown that the Framingham risk score (FRS) (5) and Mets score (6) are strong markers predicting the risk of coronary heart diseases. Furthermore, FRS is an algorithm used to predict the 10-year cardiovascular risk. It has also been found that only controlling changeable risk factors (e.g., age, sex, smoking, blood pressure, total cholesterol, triglyceride, and waist and hip circumferences) can be effective for preventive treatments in patients with diabetes (7).

Exercise has long been recognized as an important management strategy in T2D patients (8). However, adequate support is still not available to show the influence of exercise interventions on other CVD-related risk factors. According to the Canadian diabetes association (CDA) guidelines, the main lifestyle interventions to reduce the risk of CVD must include improvements in glycemic control, blood lipid levels reduction, blood pressure control, quality

(C) 2019 The Author(s); Published by Shahrekord University of Medical Sciences. This is an open-access article distributed under the terms of the Creative Commons Attribution License (http://creativecommons.org/licenses/by/4.0), which permits unrestricted use, distribution, and reproduction in any medium, provided the original work is properly cited. 
of life, and other diabetes-related coexisting complications (9). There is adequate evidence supporting the hypothesis that different vigorous exercise training can be effective interventions to reduce the cardiovascular risk profile in T2D $(10,11)$. According to the reports of a meta-analysis, improvement in cardiorespiratory fitness after HIIT was greater as compared to the increase after moderate intensity training (12). There is not enough information, however, regarding these novel cardio-metabolic risk scores and exercise training in individuals with T2D. Nonetheless, Ezeukwu et al reported that intense continuous training was better than interval training in reducing the atherogenic index of plasma in sedentary males (13). It seems that increased exercise energy expenditure in HIIT, as assessed by metabolic equivalents (METs), can result in a reduced risk of cardiovascular events (14). Therefore, the aim of this study was to compare the effects of two exercise modalities on novel cardio-metabolic risk factors in overweight women afflicted with T2D.

\section{Methods}

Subjects

This study was a single-blind randomized clinical trial conducted, on the basis of the CONSORT statement (15), in Shahrekord University in 2016. Those patients participants who had registered in Shahrekord diabetes association were selected and recruited according to the following inclusion criteria: diagnosed with T2D by a physician based on the American Diabetes Association (ADA) criteria (HbA1C $\geq$
$6.5 \%$, fasting blood glucose $\geq 126 \mathrm{mg} / \mathrm{dL}[7.0 \mathrm{mmol} / \mathrm{L}]$ ) (16), being sedentary (being sedentary is defined as no more than 20 minutes of exercise per week over the past 6 months) (17), 45-60 years old pre-menopausal women with a body mass index (BMI) between 25 and $35 \mathrm{~kg} / \mathrm{m}^{2}$, not diagnosed with type 1 diabetes, and not having lost or gained more than $5 \mathrm{~kg}$ in weight during the previous 6 months. Meanwhile, participants were excluded if they had a blood pressure $\geq 160 / 100 \mathrm{~mm} \mathrm{Hg}$, fasting triglyceride $\geq 500 \mathrm{mg} / \mathrm{dL}$, serious cardiovascular or musculoskeletal problems, thyroid disorder, cancer, hormonal disorder, kidney and liver diseases, surgery, or if they were smokers or used drugs or alcohol. In addition, it was concluded that a sample size between 10-20 subjects could clinically provide the statistical power of $80 \%$ into the effect of SIT versus combined training and a potential difference was detected in the means of $2 \%$ after the 10 -week training. Based on the power and sample size calculation, in this study, 17 subjects were determined to be included per group based on a predicted dropout rate of $20 \%$. All the participants provided the written informed consent.

Of 150 recruitments, only 54 subjects met the inclusion criteria (Figure 1). Eligible subjects were informed, verbally or in writing, about the study protocol and possible risks and benefits through involving in the study. They were also assured of the confidentiality of all their answers.

Concealed randomization in the variable blocks of 6 was conducted by a research assistant not involved in this research using a computer-generated random number

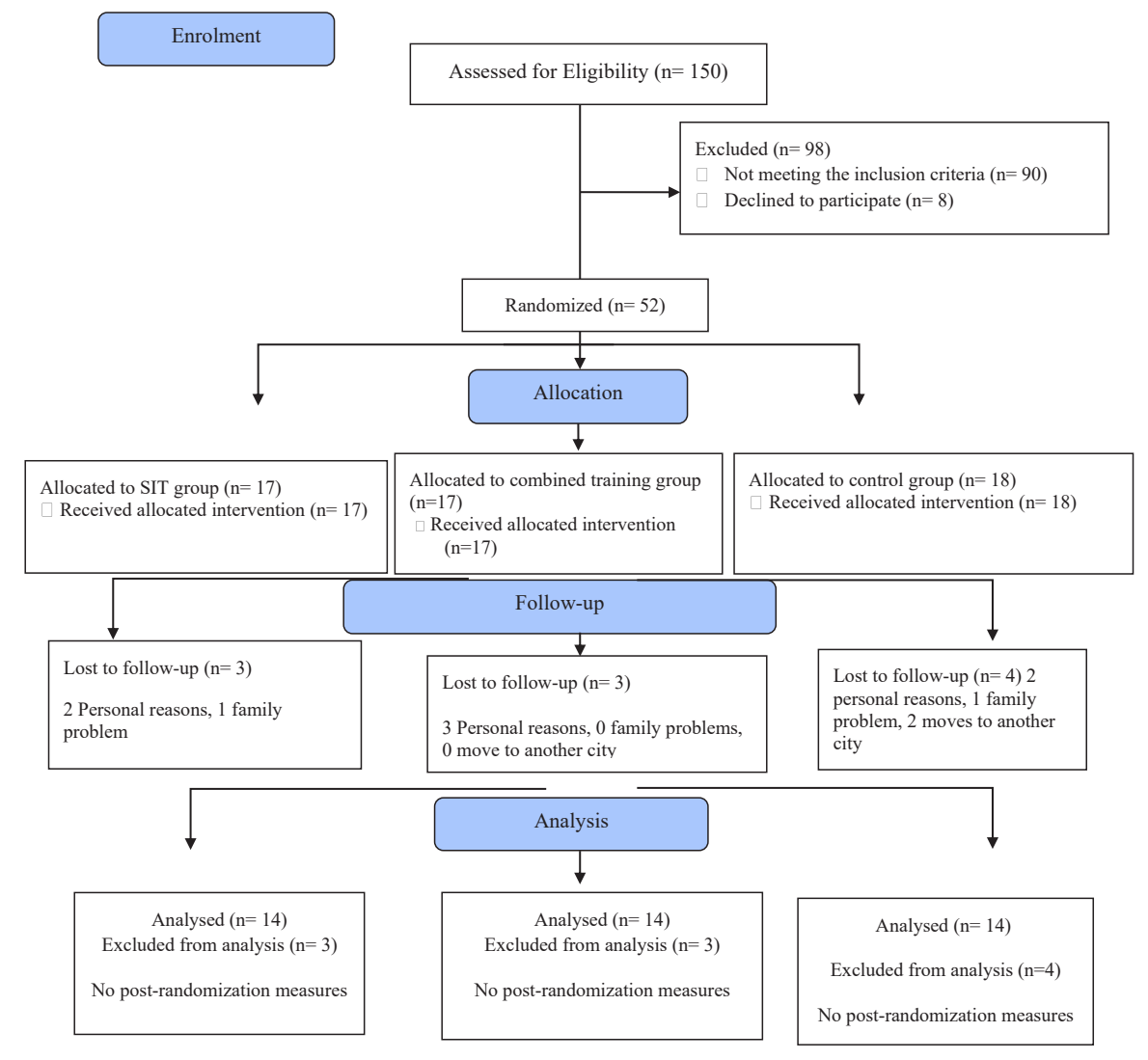

Figure 1. CONSORT 2010 flow diagram. 
sequence. Participants were stratified according to HbA1c level. Sequential treatment allocations were enclosed in numbered, opaque, sealed envelopes, and distributed by this research assistant among the groups after the baseline assessment. Participants were randomly assigned to the SIT ( $\mathrm{n}=17)$, the $\mathrm{A}+\mathrm{R}(\mathrm{n}=17)$, or the control $(\mathrm{n}=18)$ groups, respectively. Distribution of the frequency of the study participants is presented in Figure 1.

\section{Exercise training protocols}

Exercise interventions included a 10-week combined (aerobic and resistance) or SIT training in the morning 2 hours after breakfast. Subjects exercised three times per week for 50 minutes, according to the American College of Sports Medicine (ACSM) guidelines (18), and the training progressed in length and intensity (Table 1). Besides, training was supervised by the expert exercise physiologists at a clinical gym. Postprandial glucose was tested before and after the exercise sessions to find out whether the person could safely begin exercising. Because the blood glucose levels could also run high during or after high-intensity exercise through increasing glucose-raising hormone levels, when blood glucose level was less than $5.5 \mathrm{mmol} / \mathrm{L}$ (in insulin-receiving subjects) or $6.6 \mathrm{mmol} / \mathrm{L}$ (in non-insulin receivers) before the exercise, the subjects could eat a meal containing carbohydrate (25 g) and protein (7 g) (19).

\section{Combined aerobic and resistance training}

Through aerobic training program, participants were free to exercise on a treadmill or ergometer. Aerobic training progressed from $20 \mathrm{~min} / \mathrm{session}$ at $60 \%$ maximum heart rate (Max HR) in the weeks $1-2$ to $30 \mathrm{~min} /$ session at $70 \%$ Max HR in the weeks 3-10. The HR monitors (Polar T31, Oy, Kempele, Finland) were used to adjust the workload to achieve the target HR. The aerobic training was personalized by individualized increments.

Resistance training was also performed at one set of 15rep max with 15 repetitions for the first two weeks. Then, the intensity was increased from 2-3 sets of 12 to 10 max reps with 12 to 10 repetitions between the weeks 3-10 (Table 1) (20). All the resistance training were performed on weight machines and included bench and leg pressing, bending over the lateral pull down, bilateral biceps curling, and bilateral triceps pushing down.
Sprint interval training

The sprint interval training (SIT) training consisted of exercising on cycle ergometers (Ergomedic 894E Peak Bike, Monark EB; Varberg, Sweden). Each session contained a 5-minute warm-up, with $4 \times 30$ second maximum intensity intervals at the breaking wattage of the individual followed by recovery ( 2 minutes) and cool-down (4 minutes). Wattage was adjusted upward by $10 \%$ based on the performance and the perceived effort in participants who had completed the three intervals on the first SIT session. However, it was adjusted down by $10 \%$ according to the same criteria for those who were not capable of maintaining the required $120 \mathrm{rpm}$ for any interval. In addition, during the 10-week SIT, the wattage was adjusted upward in $10 \%$ increments. This was conducted to ensure that the maximum intensity was being exerted during each session if a patient had completed three intervals by maintaining more than $120 \mathrm{rpm}$ on two consecutive sessions (21).

\section{Anthropometric measures}

Body fat percentage (BF \%) was measured to the nearest $0.5 \mathrm{~mm}$ at three sites: abdominal, thigh, and supra-iliac (Lafayette Instrument Skinfold Caliper, model 01128) (22). Height without shoes and body mass were also measured using a portable stadiometer to the nearest millimeter and a calibrated digital scale to the nearest 0.1 $\mathrm{kg}$, respectively. The BMI was calculated $\left(\mathrm{kg} / \mathrm{m}^{2}\right)$ as well. Waist circumference was estimated at the midpoint between the iliac crest and the lower rib margin and recorded to the nearest centimeter. In addition, hip circumference was measured at the point of the maximal gluteal protuberance from the lateral view to the nearest centimeter. And finally, waist/hip ratio (WHR) was calculated dividing the waist circumference by the hip circumference (23).

\section{Blood analysis}

Blood samples (10 cc), from the antecubital vein in a sitting position were collected 24 hours before the exercise protocol and 48 hours after the last session of the training program within 12 hours of the fasting state.

Fasting blood glucose was measured employing the glucose oxidase method (Pars Azmoon Kit, Tehran, Iran) through auto-analyzer devices $\left(\mathrm{Hitachi}^{\circledR}\right.$, model 704, 902 made in Japan). Moreover, serum insulin concentrations were

Table 1. Exercise Training Intervention

\begin{tabular}{|c|c|c|c|c|c|c|c|c|c|c|c|}
\hline \multirow{2}{*}{ Week } & \multicolumn{5}{|c|}{ Resistance training program } & \multicolumn{3}{|c|}{ Aerobic endurance training } & \multicolumn{3}{|l|}{ SIT } \\
\hline & Set & $\begin{array}{l}\text { Repetition } \\
\text { (n) }\end{array}$ & $\begin{array}{l}\text { Rest between } \\
\text { (min) }\end{array}$ & Weight & No. (days/wk) & $\begin{array}{l}\text { Duration } \\
\text { (min) }\end{array}$ & $\begin{array}{l}\text { Intensity } \\
\text { (MHR \%) }\end{array}$ & No. (day/wk) & $\begin{array}{l}\text { Duration } \\
\text { (second) }\end{array}$ & Intensity & No. (day/wk) \\
\hline $1-2$ & 1 & 15 & $2-3$ & 15-RM & 3 & $15-20$ & 60 & 3 & $4 \times 30 s$ & All-out & 3 \\
\hline $3-4$ & 2 & 15 & $2-3$ & 15-RM & 3 & 25 & 60 & 3 & $4 \times 30 s$ & All-out & 3 \\
\hline $5-6$ & 3 & 12 & $2-3$ & 12-RM & 3 & 30 & 70 & 3 & $4 \times 30 s$ & All-out & 3 \\
\hline $7-8$ & 3 & 12 & $2-3$ & 12-RM & 3 & 30 & 70 & 3 & $4 \times 30 s$ & All-out & 3 \\
\hline $9-10$ & 3 & 10 & $2-3$ & 10-RM & 3 & 30 & 70 & 3 & $4 \times 30 s$ & All-out & 3 \\
\hline
\end{tabular}

Note. RM: Repetition maximum; MHR: Maximum heart rate; SIT: Sprint interval training. 
determined by ELISA technique using a microplate reader. Furthermore, HOMA-IR was calculated by computing the following equation (24):

(Fasting glycemia $[\mathrm{mmol} / \mathrm{L}] \times$ fasting insulin $[\mathrm{mIU} / \mathrm{l}])$ $/ 22.5$

Meanwhile, participants who used insulin injection were excluded for the HOMA-IR analysis.

Novel cardiometabolic risk scores

1. FRS = https://www.cvdriskchecksecure.com/framinghamriskscore.aspx (2017-12-04).

2. MET syndrome $Z$-Score $=$ waist $Z$ score $+B P Z$ score + glucose Z score $+\mathrm{HDL}-\mathrm{C} Z$ score + triglycerides $\mathrm{Z}$ score.

\section{Statistical analyses}

Data related to 10 participants who did not attend the post-test-assessment were excluded and only the available data of 42 participants who had completed the pre and post assessment were analyzed. The sample size was calculated based on previous researches to examine the difference in effect between SIT and A+R training. It was concluded that a sample size of $10-20$ subjects could clinically provide the statistical power of $80 \%$ into the effect of SIT versus $A+R$ training. Moreover, a difference in the means of $2 \%$ was detected after 10 weeks of training. A KolmogorovSmirnov test was used to check data normality. Baseline characteristics of the groups were compared running a oneway analysis of variance (ANOVA) or Kruskal-Wallis test if the data was not normally distributed. Paired $t$ test was also applied to compare pretest and posttest results in each group. A one-way between groups ANOVA was conducted to compare the number of changes in the experimental and control groups after 10 weeks of training. When a significant $F$ value was achieved, post hoc Tukey HSD test was used to find the differences between various groups. Statistical significance was accepted at $P<0.05$.

Results

The data related to 42 participants with the mean age of $55.07 \pm 5.92$ years old (dropout rate: 19.2\%) who had completed the pre- and post-assessment was analyzed. The participants flow through the study can be found in the CONSORT flowchart in Figure 1. Twenty-seven subjects were treated with oral hypoglycemic medications while 20 of them were injected with insulin. And eventually, five participants were treated with the combination therapy of insulin injection and oral drugs. The baseline characteristics of the participants are represented in Table 2.

\section{Adverse events}

No clinically severe adverse events were identified and reported during a 10 -week intervention. However, most patients reported muscle soreness in their legs during SIT (78\%) and $A+R$ training (82\%). The results were based on 14 participants in each of the control, SIT, and combined groups.

At the baseline, no differences were observed between the combined, the SIT, and the control groups regarding body mass, body fat percentage, BMI, WHR, FBG, and HbA1c (Table 2).

There were no statistically significant differences in body mass, BMI, body fat, WHR, MAP, HDL, and TG between the groups. However, significant differences were observed in WC $(P=0.001)$ and HbA1c $(P=0.006)$.

Table 2. Descriptive characteristics of participants at baseline

\begin{tabular}{|c|c|c|c|c|}
\hline Characteristics & SIT group $(n=14)$ & Combined training group $(n=14)$ & Control $(n=14)$ & $P$-value \\
\hline Age (y) & $55.36 \pm 5.94$ & $54.14 \pm 5.43$ & $55.71 \pm 6.40$ & 0.765 \\
\hline Height (cm) & $162.7 \pm 7.61$ & $160.5 \pm 4.99$ & $159.3 \pm 5.48$ & 0.34 \\
\hline Weight (kg) & $77.35 \pm 11.99$ & $71.44 \pm 13.20$ & $76.30 \pm 9.59$ & 0.711 \\
\hline BMI $\left(\mathrm{kg} / \mathrm{m}^{2}\right)$ & $29.29 \pm 3.19$ & $30.57 \pm 2.97$ & $29.70 \pm 4.17$ & 0.613 \\
\hline Body Fat (\%) & $41.14 \pm 4.34$ & $42.57 \pm 2.17$ & $42.64 \pm 4.95$ & 0.541 \\
\hline WHR & $1.00 \pm 0.13$ & $1.03 \pm 0.19$ & $1.01 \pm 0.18$ & 0.904 \\
\hline $\mathrm{SBP}(\mathrm{mm} \mathrm{Hg})$ & $133.57 \pm 18.64$ & $131.43 \pm 16.58$ & $127.14 \pm 23.99$ & 0.97 \\
\hline $\mathrm{DBP}(\mathrm{mm} \mathrm{Hg})$ & $77.86 \pm 8.93$ & $77.14 \pm 12.04$ & $74.29 \pm 12.23$ & 0.672 \\
\hline $\mathrm{VO}_{2} \max (\mathrm{mL} / \mathrm{kg} / \mathrm{min})$ & $32.51 \pm 7.30$ & $34.37 \pm 5.37$ & $31.06 \pm 5.33$ & 0.362 \\
\hline $\mathrm{FBG}(\mathrm{mg} / \mathrm{dL})$ & $210.07 \pm 32.91$ & $214.64 \pm 27.67$ & $177.29 \pm 47.09$ & 0.021 \\
\hline Insulin $(\mu \mathrm{U} / \mathrm{mL})$ & $10.08 \pm 5.43$ & $10.37 \pm 5.35$ & $9.54 \pm 4.04$ & 0.230 \\
\hline HbA1c (\%) & $9.64 \pm 1.07$ & $9.49 \pm 0.85$ & $9.01 \pm 0.51$ & 0.005 \\
\hline HOMA-IR & $314.24 \pm 160.05$ & $282.29 \pm 101.38$ & $272.51 \pm 91.32$ & 0.640 \\
\hline $\mathrm{HDL}(\mathrm{mg} / \mathrm{dL})$ & $54.50 \pm 4.48$ & $49.07 \pm 8.26$ & $55.43 \pm 8.55$ & 0.058 \\
\hline $\mathrm{TG}(\mathrm{mg} / \mathrm{dL})$ & $149.21 \pm 74.72$ & $159.07 \pm 28.64$ & $179.14 \pm 79.36$ & 0.470 \\
\hline WC $(\mathrm{cm})$ & $97.43 \pm 11.83$ & $102.14 \pm 8.96$ & $102.21 \pm 10.67$ & 0.398 \\
\hline MAP (mm Hg) & $8.85 \pm 1.16$ & $9.47 \pm 1.26$ & $9.61 \pm 1.13$ & 0.213 \\
\hline
\end{tabular}

Note. BMI: body mass index; HDL: high density lipoprotein; TG: triglyceride; WC: waist circumference; MAP: Mean arterial pressure. One-way analysis of variance (ANOVA) or Kruskal-Wallis test was used for baseline characteristics of the groups when the data was not normally distributed. 
Conducting paired $t$ test and comparing within groups $P$ values, however, revealed significant differences in WC $(P$ $=0.001), \operatorname{HbA1c}(P=0.001)$, and TG $(P=0.025)$ in SIT group and also in WC $(P=0.001), \operatorname{HbA1c}(P=0.010)$, and MAP $(P=0.014)$ in the combined group. (Table 3$)$.

Post hoc Tukey HSD test also showed significant differences in WC between SIT and control groups $(P=$ 0.003). Besides, significant differences were found between combined and control groups $(P=0.021)$ in this respect. In addition, significant differences were observed in HbA1c between SIT and control groups $(P=0.001)$, and also between the combined and control groups $(P=0.043)$.

The results of the effects of the 10 -week combined resistance/endurance and SIT intervention training on novel cardiometabolic indices are presented in Table 4.

Comparing within-group changes demonstrated significant improvements on FRS $(P<0.001)$ in the SIT group after 10 weeks as compared to the baseline. In addition, there were significant changes regarding FRS ( $P$ $=0.001)$ in the combined training group after 10 weeks as compared to the baseline. However, no significant changes were detected respecting Mets in the SIT group after 10 weeks $(P=0.187)$. Similarly, there were no significant changes in Mets in the combined training group after 10 weeks $(P=0.279)$.

Moreover, the results of one-way ANOVA test showed that there were significant differences between the groups in FRS $(F=8.861, P=0.001)$, but not in Mets $(F=1.922$, $P=0.160)$.

Conversely, however, post-hoc Tukey test analysis revealed significant differences in FRS either between SIT and combined training groups $(P=0.018)$ and SIT and control groups $(P=0.001)$.

In the same vein, there was a significant reduction in fasting blood glucose in the SIT group $(P<0.001)$ after 10 weeks. Besides, a significant decrease was observed in the insulin level and HOMA-IR in the combined training $(P<0.001)$ and SIT $(P<0.001)$ groups after the 10 -week intervention.

Furthermore, the results of ANOVA demonstrated that there were no significant differences in fasting blood glucose concentrations $(F=1.853, P=0.171)$. However, significant differences were detected between the groups in insulin $(F=3.622, P=0.036)$ and HOMA-IR $(F=5.511$, $P=0.008)$ levels.

Moreover, analyzing the results of post-hoc Tukey test it was revealed that significant differences existed between SIT and control groups $(P=0.029)$ as well as combined

Table 3. Comparison of changes in anthropometric variables at baseline and 10-week exercise interventions

\begin{tabular}{|c|c|c|c|c|c|c|}
\hline Variables & Test & SIT group & Combined training group & Control group & $\mathbf{F}$ & $P$-value between groups \\
\hline \multirow{3}{*}{$\begin{array}{l}\text { Body weight } \\
(\mathrm{kg})\end{array}$} & Pretest & $77.35 \pm 11.99$ & $71.44 \pm 13.20$ & $76.30 \pm 9.58$ & & \multirow{3}{*}{0.353} \\
\hline & Posttest & $77.00 \pm 12.34$ & $71.19 \pm 13.10$ & $75.55 \pm 9.23$ & 1.069 & \\
\hline & $P$-value within group & 0.372 & 0.483 & 0.483 & & \\
\hline \multirow{3}{*}{$\mathrm{BMI}\left(\mathrm{kg} / \mathrm{m}^{2}\right)$} & Pretest & $29.57 \pm 2.77$ & $30.57 \pm 2.97$ & $29.70 \pm 4.17$ & & \multirow{3}{*}{0.718} \\
\hline & Posttest & $27.19 \pm 7.82$ & $31.58 \pm 8.61$ & $29.57 \pm 4.14$ & 0.334 & \\
\hline & $P$-value within group & 0.368 & 0.680 & 0.680 & & \\
\hline \multirow{3}{*}{ Body fat (\%) } & Pretest & $48.64 \pm 2.23$ & $45.57 \pm 2.17$ & $42.64 \pm 4.95$ & & \multirow{3}{*}{0.204} \\
\hline & Posttest & $41.14 \pm 4.34$ & $41.43 \pm 4.18$ & $44.50 \pm 2.17$ & 1.657 & \\
\hline & $P$-value within group & 0.317 & 0.347 & 0.347 & & \\
\hline \multirow{3}{*}{ WHR (cm) } & Pretest & $1.00 \pm 0.13$ & $1.03 \pm 0.19$ & $1.01 \pm 0.18$ & & \multirow{3}{*}{0.873} \\
\hline & Posttest & $0.95 \pm 0.05$ & $0.96 \pm 0.08$ & $0.97 \pm 0.06$ & 0.136 & \\
\hline & $P$ value within group & 0.148 & 0.202 & 0.374 & & \\
\hline WC $(\mathrm{cm})$ & $\begin{array}{c}\text { Pretest } \\
\text { Posttest } \\
P \text { value within group }\end{array}$ & $\begin{array}{c}102.21 \pm 10.67 \\
92.07 \pm 6.52 \\
0.001\end{array}$ & $\begin{array}{c}102.14 \pm 8.96 \\
96.00 \pm 6.55 \\
0.001\end{array}$ & $\begin{array}{c}97.43 \pm 11.83 \\
96.07 \pm 9.78 \\
0.362\end{array}$ & 8.012 & $0.001^{*}$ \\
\hline $\begin{array}{l}\mathrm{MAP}(\mathrm{mm} \\
\mathrm{Hg})\end{array}$ & $\begin{array}{c}\text { Pretest } \\
\text { Posttest } \\
P \text { value within group }\end{array}$ & $\begin{array}{c}14.13 \pm 1.92 \\
13.02 \pm 0.96 \\
0.060\end{array}$ & $\begin{array}{c}13.78 \pm 1.56 \\
13.02 \pm 1.24 \\
0.014\end{array}$ & $\begin{array}{c}13.39 \pm 2.35 \\
12.67 \pm 2.63 \\
0.169\end{array}$ & 0.221 & 0.803 \\
\hline $\mathrm{HbA1c}(\%)$ & $\begin{array}{c}\text { Pretest } \\
\text { Posttest } \\
P \text { value within group }\end{array}$ & $\begin{array}{c}9.64 \pm 1.07 \\
7.82 \pm 0.93 \\
0.001\end{array}$ & $\begin{array}{c}9.49 \pm 0.85 \\
8 . .25 \pm 1.22 \\
0.010\end{array}$ & $\begin{array}{c}9.10 \pm 0.51 \\
9.12 \pm 1.41 \\
0.954\end{array}$ & 5.865 & $0.006^{*}$ \\
\hline $\mathrm{HDL}(\mathrm{mg} / \mathrm{dL})$ & $\begin{array}{c}\text { Pretest } \\
\text { Posttest } \\
P \text { value within group }\end{array}$ & $\begin{array}{c}55.43 \pm 8.55 \\
58.50 \pm 1.22 \\
0.191\end{array}$ & $\begin{array}{c}49.07 \pm 8.26 \\
50.79 \pm 8.64 \\
0.539\end{array}$ & $\begin{array}{c}54.50 \pm 4.48 \\
51.21 \pm 6.27 \\
0.103\end{array}$ & 2.122 & 0.133 \\
\hline TG (mg/dL) & $\begin{array}{c}\text { Pretest } \\
\text { Posttest } \\
P \text { value within group }\end{array}$ & $\begin{array}{c}179.14 \pm 79.36 \\
125.00 \pm 21.75 \\
0.025\end{array}$ & $\begin{array}{c}159.07 \pm 28.64 \\
135.07 \pm 45.86 \\
0.058\end{array}$ & $\begin{array}{c}149.21 \pm 74.72 \\
126.00 \pm 40.23 \\
0.311\end{array}$ & 0.867 & 0.428 \\
\hline
\end{tabular}

Note. BMI: body mass index; HDL: high density lipoprotein; TG: triglyceride; WC: waist circumference; MAP: Mean arterial pressure; WHR: Waist-hip ratio; SIT: Short sprint interval training; Combined training: resistance and aerobic training; Control group: subjects who did not participated in exercise training; BMI: body mass index. WHR: circumference waist of hip ratio. Paired $t$-test were used to compare pretest and posttest in each group. An ANOVA was also conducted for between-group comparisons. 
Table 4. Comparison of changes in cardiometabolic indices before and after 10-week exercise interventions

\begin{tabular}{|c|c|c|c|c|c|c|}
\hline Variables & Test & SIT group & Combined training group & Control group & $F$ & $P$ value between groups \\
\hline \multirow{3}{*}{ MetS } & Pretest & $-0.41 \pm 4.00$ & $0.84 \pm 4.04$ & $0.01 \pm 3.82$ & & \\
\hline & Posttest & $2.02 \pm 3.72$ & $-1.10 \pm 6.81$ & $0.14 \pm 3.30$ & 1.922 & 0.160 \\
\hline & $P$-value within group & 0.187 & 0.279 & 0.911 & & \\
\hline \multirow{3}{*}{ FRS $(\%)$} & Pretest & $12.14 \pm 2.68$ & $10.35 \pm 2.73$ & $10.07 \pm 3.51$ & & \\
\hline & Posttest & $7.71 \pm 2.33$ & $8.28 \pm 3.38$ & $8.85 \pm 3.46$ & 8.861 & $0.001 *$ \\
\hline & $P$-value within group & 0.001 & 0.001 & 0.098 & & \\
\hline
\end{tabular}

Note. SIT: Short sprint interval training; Combined training: resistance and aerobic training; Control group: subjects who did not participate in exercise training; MetS: Metabolic syndrome scores; FRS: Framingham risk score. Paired t-test were used to compare pretest and posttest in each group. An ANOVA was also conducted for between-group comparisons.

Table 5. Comparison of changes in some serum variables at baseline and 10-week exercise interventions

\begin{tabular}{|c|c|c|c|c|c|c|}
\hline Variables & Test & SIT group & Combined training group & Control group & $\mathbf{F}$ & $P$ value between groups \\
\hline $\mathrm{FBG}(\mathrm{mg} / \mathrm{dL})$ & $\begin{array}{l}\text { Pretest } \\
\text { Posttest } \\
P \text { value within group }\end{array}$ & $\begin{array}{l}210.07 \pm 32.90 \\
147.92 \pm 41.17 \\
<0.001\end{array}$ & $\begin{array}{l}216.00 \pm 63.08 \\
163.85 \pm 71.47 \\
0.162\end{array}$ & $\begin{array}{l}177.28 \pm 47.09 \\
183.26 \pm 60.70 \\
0.690\end{array}$ & 1.853 & 0.171 \\
\hline $\begin{array}{l}\text { Serum } \\
\text { insulin }(\mu \mathrm{U} / \\
\mathrm{mL})\end{array}$ & $\begin{array}{l}\text { Pretest } \\
\text { Posttest } \\
P \text { value within group }\end{array}$ & $\begin{array}{l}7.72 \pm 2.63 \\
4.97 \pm 1.30 \\
0.001\end{array}$ & $\begin{array}{l}9.10 \pm 2.62 \\
5.93 \pm 2.24 \\
0.001\end{array}$ & $\begin{array}{l}6.57 \pm 2.06 \\
6.21 \pm 2.06 \\
0.08\end{array}$ & 3.622 & 0.036 \\
\hline HOMA-IR & $\begin{array}{l}\text { Pretest } \\
\text { Posttest } \\
P \text { value within group }\end{array}$ & $\begin{array}{l}98.33 \pm 3.08 \\
93.44 \pm 3.03 \\
0.001\end{array}$ & $\begin{array}{l}95.40 \pm 3.08 \\
92.50 \pm 3.18 \\
0.001\end{array}$ & $\begin{array}{l}97.44 \pm 4.36 \\
97.00 \pm 4.53 \\
0.732\end{array}$ & 5.511 & 0.008 \\
\hline
\end{tabular}

Note. SIT: short sprint interval training; Combined training: resistance and aerobic training; Control group: subjects who did not participate in exercise training; FBG: fasting blood glucose; HOMA-IR: Homeostasis model assessment. Paired t-test were used to compare pretest and posttest in each group. An ANOVA was conducted for between-group comparisons.

and control groups $(P=0.022)$ regarding insulin level. In addition, there were significant differences in HOMA-IR level between SIT and control groups $(P=0.002)$ and also combined and control groups $(P=0.013)$ (Table 5).

\section{Discussion}

To the best knowledge of the authors, the current study can be regarded as the first randomized controlled trial (RCT) comparing the effects of different modes of exercise modalities on novel cardio-metabolic risk factors among women with T2D. The results of this study demonstrated that SIT was a more potent stimulus than combined training in improving FRS. Additionally, SIT and combined training did not lead to more powerful significant changes in Mets, body composition in terms of body mass, BMI, WHR, and BF percentage in women suffering from diabetes.

No differences were found in MetS Z-score changes between SIT and combined training. In addition, there were no significant changes in MetS Z-score from the baseline to the post-exercise training in all groups. Furthermore, the beneficial effects of exercise on the MetS Z-score were achieved without concomitantly altering body composition. It has been revealed that fat mass changes were not correlated with MetS Z-score (26). Interestingly, no significant reduction was observed in body composition in all groups. Apparently, exercise-dependent changes in body composition or more precisely, changes in body mass, BF percentage, and WHR were not important factors in reducing the cardio-metabolic risk score (26). The results of this study confirmed that no significant change in the MetS Z-score would be possible in the absence of a change in body composition. The strength of the present study was the application of novel MetS Z-score to evaluate the effects of different exercise modalities. Confirming the present results, Gates illustrated that 16 weeks of aerobic training did not change the MetS Z-score (25). In the same vein, Johnson et al found no superiority of SIT over moderate intensity training in overweight/obese subjects (27). Earnest et al also showed similar reductions in the MetS Z-score in overweight males performing high intensity and moderate training (28). Due to methodological differences across various studies such as differences in gender, age, health, weight and physical fitness status, medication, mode and intensity of exercise, and duration of the training program (29), drawing general conclusions is difficult (30). According to some studies, it could be speculated that none of these training methods might induce improvements in the metabolism, metabolic capacity, and body composition $(30,31)$. The present study hypothesized that regular SIT and combined training could reduce the risk of CVD inT2D. It has also been proven that both exercise modalities could be recommended for T2Dpatients. This finding is consistent with the result obtained by Ramos et al, who found that low-volume HIIT could be as effective as moderate-intensity continuous training in reduction of the MetS Z-score (32).

Furthermore, the results of the present study showed 
that applying regular SIT and combined training could reduce the risks of CVD for 10 years. This improvement may result from the decreased systolic and diastolic blood pressure and also improvements of lipid profile (33), as was confirmed in the current study. Significant improvements in systolic and diastolic blood pressure and lipid profile might be due to these reductions in FRS (34). The FRS reduction results are in agreement with those obtained by Amin-Shokravi et al (33) and Tuley et al (34). It seems that the severity of applied exercise training in this study was sufficient to bring about changes in FRS.

In addition, Fisher et al demonstrated that both HIT and continuous moderate intensity training were associated with improvements in cardio-metabolic risk factors (i.e., body fat percent, cholesterol, VLDL, HDL, triglycerides, and $\mathrm{VO}_{2}$ peak) in overweight men (35).

The results of the present study also indicated that compared to the baseline values, serum insulin and HOMAIR were changed after 10 weeks of SIT and combined training in diabetic women. It was revealed that SIT and combined training programs that had been performed 3 days a week (for 10 weeks) were safe and well-tolerated by patients afflicted with T2D. Besides, such programs were found to be effective in improving the serum insulin levels and HOMA-IR.

The above-mentioned findings seem to be in conformity with the results of those studies in which HIT was accompanied by improving glycemic control in obese and/or patients with T2D (36-38). Several studies have recently demonstrated that SIT appeared to be a very timeefficient exercise regime that shared many of the metabolic adaptations as traditional endurance exercise training did $(36,39,40)$. However, in another study, it was found that combined exercise training had a more considerable total duration of exercise and calorie consumption as compared with the time when each type of training was performed alone (41). Despite the fact that such patients tolerate this exercise mode, it seems that more calories could be consumed following this exercise prescription.

Some of the strengths of the present study are as follows: employing the RCT design, inclusion of two different training programs in the same study, direct personalized exercise training during all the training sessions, and using a novel cardio-metabolic risk score to evaluate the effects of different exercise modalities on the risk of cardio-metabolic diseases, which altogether provided an increased level of accuracy and sensitivity.

The small sample size, significant dropout rate, and supervised exercise only in the experimental groups can be mentioned as the limitations of the present study. Moreover, the non-significant reductions of body composition parameters, which can be attributed to the lack of diet control, can be considered as another limitation of the study. The current study can yield some insights into selecting the type of exercises that can be more helpful for the cardio-metabolic risk reduction. However, this exercise schedule may not be suitable for real-life settings as adequacy of the exercise cannot be quantified. Besides, many patients with T2Dmay not have the facilities to do such exercises. This is also another limitation of this study.

\section{Conclusion}

The results of the present study confirmed the importance of SIT and combined training program in improving T2D and novel cardio-metabolic risk scores, despite the fact that some studies had shown that combined training (aerobic and resistance) and SIT interventions could improve glucose homeostasis in overweight women afflicted with T2D. The results also highlighted that SIT training could be an effective training method to improve some novel cardiometabolic risk scores in overweight women with T2D. Furthermore, even without weight loss during the course of the 10-week exercise, there was a significant reduction in anthropometric variables, suggesting that weight loss was not mandatory for the healthy body composition.

Conflict of interests

None.

Ethical considerations

The protocol was registered in the Iranian clinical trial registry (identifier: IRCT20141118019995N10). The study was approved by the Ethics Committee of Shahrekord University (No. SKU94/210).

Financial support

The current study was supported by a grant from Shahrekord University of Medical Sciences (grant No. 95GRN1M895).

Acknowledgements

The authors would like to thank all the participants of this study.

References

1. Sarwar N, Gao P, Seshasai SR, Gobin R, Kaptoge S, Di Angelantonio $\mathrm{E}$, et al. Diabetes mellitus, fasting blood glucose concentration, and risk of vascular disease: a collaborative meta-analysis of 102 prospective studies. Lancet. 2010;375(9733):2215-22. doi: 10.1016/s0140-6736(10)60484-9.

2. Shah AD, Langenberg C, Rapsomaniki E, Denaxas S, PujadesRodriguez M, Gale CP, et al. Type 2 diabetes and incidence of cardiovascular diseases: a cohort study in 1.9 million people. Lancet Diabetes Endocrinol. 2015;3(2):105-13. doi: 10.1016/ s2213-8587(14)70219-0.

3. Yip YB, Ho SC, Chan SG. Tall stature, overweight and the prevalence of low back pain in Chinese middle-aged women. Int J Obes Relat Metab Disord. 2001;25(6):887-92. doi: 10.1038/ sj.ijo.0801557.

4. Kanaya AM, Grady D, Barrett-Connor E. Explaining the sex difference in coronary heart disease mortality among patients with type 2 diabetes mellitus: a meta-analysis. Arch Intern Med. 2002;162(15):1737-45.

5. Hosseinpanah F, Barzin M, Mirbolouk M, Abtahi H, Cheraghi L, Azizi F. Lipid accumulation product and incident cardiovascular events in a normal weight population: Tehran Lipid and Glucose Study. Eur J Prev Cardiol. 2016;23(2):187-93. doi: 10.1177/2047487314558771.

6. Han L, Fu KL, Zhao J, Wang ZH, Tang MX, Wang J, et al. Visceral adiposity index score indicated the severity of coronary heart disease in Chinese adults. Diabetol Metab Syndr. 2014;6(1):143. doi: 10.1186/1758-5996-6-143.

7. Chamnan P, Simmons RK, Sharp SJ, Griffin SJ, Wareham NJ. Cardiovascular risk assessment scores for people with diabetes: 
a systematic review. Diabetologia. 2009;52(10):2001-14. doi: 10.1007/s00125-009-1454-0.

8. Colberg SR, Albright AL, Blissmer BJ, Braun B, Chasan-Taber L, Fernhall B, et al. Exercise and type 2 diabetes: American College of Sports Medicine and the American Diabetes Association: joint position statement. Exercise and type 2 diabetes. Med Sci Sports Exerc. 2010;42(12):2282-303. doi: 10.1249/ MSS.0b013e3181 eeb61c

9. Chudyk A, Petrella RJ. Effects of exercise on cardiovascular risk factors in type 2 diabetes: a meta-analysis. Diabetes Care. 2011;34(5):1228-37. doi: 10.2337/dc10-1881.

10. Balducci S, Zanuso S, Cardelli P, Salvi L, Bazuro A, Pugliese $\mathrm{L}$, et al. Effect of high- versus low-intensity supervised aerobic and resistance training on modifiable cardiovascular risk factors in type 2 diabetes; the Italian Diabetes and Exercise Study (IDES). PLoS One. 2012;7(11):e49297. doi: 10.1371/journal. pone.0049297.

11. Paluch AE, Church TS, Blair SN. Effect of an Intensive Exercise Intervention Strategy on Modifiable Cardiovascular Risk Factors in Subjects with Type 2 Diabetes Mellitus. Curr Cardiovasc Risk Rep. 2011;5(6):481-3. doi: 10.1007/s12170-011-0203-3.

12. Weston KS, Wisloff $U$, Coombes JS. High-intensity interval training in patients with lifestyle-induced cardiometabolic disease: a systematic review and meta-analysis. Br J Sports Med. 2014;48(16):1227-34. doi: 10.1136/bjsports-2013-092576.

13. Ezeukwu AO, Agwubike EO, Uadia PO. Differential Effects of Continuous and Interval Exercise Training on the Atherogenic Index of Plasma in the Non-Obese Young Male. Acta Cardiol Sin. 2015;31(4):337-44.

14. Tanasescu M, Leitzmann MF, Rimm EB, Willett WC, Stampfer MJ, $\mathrm{Hu} \mathrm{FB}$. Exercise type and intensity in relation to coronary heart disease in men. JAMA. 2002;288(16):1994-2000

15. Pandis N, Chung B, Scherer RW, Elbourne D, Altman DG. CONSORT 2010 statement: extension checklist for reporting within person randomised trials. BMJ. 2017;357:j2835. doi: 10.1136/bmj.j2835.

16. Standards of medical care in diabetes--2014. Diabetes Care. 2014;37 Suppl 1:S14-80. doi: 10.2337/dc14-S014.

17. Bennett JA, Winters-Stone K, Nail LM, Scherer J. Definitions of sedentary in physical-activity-intervention trials: a summary of the literature. J Aging Phys Act. 2006;14(4):456-77.

18. Albright A, Franz M, Hornsby G, Kriska A, Marrero D, Ullrich I, et al. American College of Sports Medicine position stand. Exercise and type 2 diabetes. Med Sci Sports Exerc. 2000;32(7):1345-60.

19. Castaneda C, Layne JE, Munoz-Orians L, Gordon PL, Walsmith J, Foldvari $\mathrm{M}$, et al. A randomized controlled trial of resistance exercise training to improve glycemic control in older adults with type 2 diabetes. Diabetes Care. 2002;25(12):2335-41.

20. Larose J, Sigal RJ, Khandwala F, Kenny GP. Comparison of strength development with resistance training and combined exercise training in type 2 diabetes. Scand J Med Sci Sports. 2012;22(4):e45-54. doi: 10.1111/j.1600-0838.2011.01412.x.

21. Higgins TP, Baker MD, Evans SA, Adams RA, Cobbold C. Heterogeneous responses of personalised high intensity interval training on type 2 diabetes mellitus and cardiovascular disease risk in young healthy adults. Clin Hemorheol Microcirc. 2015;59(4):365-77. doi: 10.3233/ch-141857.

22. Ball SD, Altena TS, Swan PD. Comparison of anthropometry to DXA: a new prediction equation for men. Eur J Clin Nutr. 2004;58(11):1525-31. doi: 10.1038/sj.ejcn.1602003.

23. Han TS, Feskens EJ, Lean ME, Seidell JC. Associations of body composition with type 2 diabetes mellitus. Diabet Med. 1998;15(2):129-35. doi: 10.1002/(sici)10969136(199802)15:2<129::aid-dia535>3.0.co;2-2.

24. Ahmadizad S, Haghighi AH, Hamedinia MR. Effects of resistance versus endurance training on serum adiponectin and insulin resistance index. Eur J Endocrinol. 2007;157(5):625-31. doi: 10.1530/eje-07-0223.

25. Gates T. Effect of Exercise Training on Metabolic Syndrome z-score: the Association of C-reactive protein. East Carolina
University; 2015

26. Ramirez-Velez R, Tordecilla-Sanders A, Tellez TL, Camelo-Prieto D, Hernandez-Quinonez PA, Correa-Bautista JE, et al. Similar cardiometabolic effects of high- and moderate-intensity training among apparently healthy inactive adults: a randomized clinical trial. J Transl Med. 2017;15(1):118. doi: 10.1186/s12967-0171216-6.

27. Johnson JL, Slentz CA, Houmard JA, Samsa GP, Duscha BD Aiken LB, et al. Exercise training amount and intensity effects on metabolic syndrome (from Studies of a Targeted Risk Reduction Intervention through Defined Exercise). Am J Cardiol. 2007;100(12):1759-66. doi: 10.1016/j.amjcard.2007.07.027.

28. Earnest CP, Lupo M, Thibodaux J, Hollier C, Butitta B, Lejeune E, et al. Interval training in men at risk for insulin resistance. Int J Sports Med. 2013;34(4):355-63. doi: 10.1055/s-0032-1311594.

29. Jelleyman C, Yates T, O'Donovan G, Gray LJ, King JA, Khunti K, et al. The effects of high-intensity interval training on glucose regulation and insulin resistance: a meta-analysis. Obes Rev. 2015;16(11):942-61. doi: 10.1111/obr.12317.

30. Batacan RB Jr, Duncan MJ, Dalbo VJ, Tucker PS, Fenning AS Effects of high-intensity interval training on cardiometabolic health: a systematic review and meta-analysis of intervention studies. Br J Sports Med. 2017;51(6):494-503. doi: 10.1136/ bjsports-2015-095841.

31. Kessler HS, Sisson SB, Short KR. The potential for high-intensity interval training to reduce cardiometabolic disease risk. Sports Med. 2012;42(6):489-509. doi: 10.2165/11630910-00000000000000.

32. Ramos JS, Dalleck LC, Borrani F, Beetham KS, Wallen MP, Mallard AR, et al. Low-Volume High-Intensity Interval Training Is Sufficient to Ameliorate the Severity of Metabolic Syndrome. Metab Syndr Relat Disord. 2017;15(7):319-28. doi: 10.1089/ met.2017.0042.

33. Amin-Shokravi F, Rajabi R, Ziaee N. Exercise Effects on Risk of Cardiovascular Disease among Iranian Women. Asian J Sports Med. 2011;2(1):37-43

34. Tully MA, Cupples ME, Chan WS, McGlade K, Young IS. Brisk walking, fitness, and cardiovascular risk: a randomized controlled trial in primary care. Prev Med. 2005;41(2):622-8. doi: 10.1016/j. ypmed.2004.11.030.

35. Fisher G, Brown AW, Bohan Brown MM, Alcorn A, Noles C, Winwood L, et al. High Intensity Interval- vs Moderate IntensityTraining for Improving Cardiometabolic Health in Overweight or Obese Males: A Randomized Controlled Trial. PLoS One. 2015;10(10):e0138853. doi: 10.1371/journal.pone.0138853.

36. Whyte LJ, Gill JM, Cathcart AJ. Effect of 2 weeks of sprint interval training on health-related outcomes in sedentary overweight/ obese men. Metabolism. 2010;59(10):1421-8. doi: 10.1016/j. metabol.2010.01.002.

37. Hamed NS, Abd-elraoof NAL, Raoof NALA. Effect of high intensity interval training on diabetic obese women with polyneuropathy: a randomized controlled clinical trial. Phys Ther Rehabil. 2014;1(1): 1-8. doi: 10.7243/2055-2386-1-4

38. Francois ME, Little JP. Effectiveness and safety of high-intensity interval training in patients with type 2 diabetes. Diabetes Spectr. 2015;28(1):39-44. doi: 10.2337/diaspect.28.1.39.

39. Burgomaster KA, Hughes SC, Heigenhauser G), Bradwell SN Gibala MJ. Six sessions of sprint interval training increases muscle oxidative potential and cycle endurance capacity in humans. J Appl Physiol (1985). 2005;98(6):1985-90. doi: 10.1152/ japplphysiol.01095.2004.

40. Richards JC, Johnson TK, Kuzma JN, Lonac MC, Schweder MM, Voyles WF, et al. Short-term sprint interval training increases insulin sensitivity in healthy adults but does not affect the thermogenic response to beta-adrenergic stimulation. J Physiol. 2010;588(Pt 15):2961-72. doi: 10.1113/jphysiol.2010.189886.

41. Sigal RJ, Kenny GP, Boule NG, Wells GA, Prud'homme D, Fortier $M$, et al. Effects of aerobic training, resistance training, or both on glycemic control in type 2 diabetes: a randomized trial. Ann Intern Med. 2007;147(6):357-69. 